\title{
Effect of Compression Thickness on Performance of Gas Diffusion Layer of Direct Methanol Fuel Cells
}

\author{
Yong-Sheen Hwang', Hoon $\mathrm{Choi}^{2}$, Gu Young $\mathrm{Cho}^{3}$, Yoon Ho Lee ${ }^{3}$, and Suk-won Cha ${ }^{3, \#}$ \\ 1 Korea Construction Equipment Technology Institute, 36, Sandan-ro, Gunsan-si, Jeollabuk-do, 573-540 Republic of Korea \\ 2 Hyundai Heavy Industry Co. LTD. 17-10 Mabuk-ro 240beon-gil, Giheunng-gu, Yongin-si, Gyeonggi-do, 446-912, Republic of Korea \\ 3 Department of Mechanical and Aerospace Engineering at Seoul National University, San 56-1, Sillim9-dong, Kwanak-gu, Seoul 151-744, Republic of Korea \\ \# Corresponding Author / E-mail: swcha@snu.ac.kr, TEL: +82-2-880-1700, FAX: +82-2-880-1696
}

KEYWORDS: Compression ratio, Ohmic loss, Mass transport loss, Current collector, PTFE gasket

This study considers the performance of a direct methanol fuel cell (DMFC) unit for the various compression ratios of a gas diffusion layer $(G D L)$ on the cathode side. A performance of fuel cells is significantly influenced by the compression ratio of the GDL. The compression ratio of the GDL can be directly controlled by the concentration compression force at the central area of the cell and gasket thickness. The balancing of the compression ratio is an important factor to increase the unit cell performance of DMFCs. In this study, the performance test of the unit cell for varying compression ratio of a GDL on the cathode side is carried out. We describe how the compression ratio affects the stack performance by the variation of compression force for two different kinds of current collectors, which directly compresses the central area of the unit cell with varying gasket thickness. This study also suggests a method to show the effect of mass transport loss by amplitude of voltage fluctuation and the unit cell relationship between the pressure drop information and the peak power of the unit cell.

\section{Introduction}

A fuel cell is one of the promising electric conversion devices. There are various type of fuel cells, like solid oxide fuel cell(SOFC), proton exchange membrane fuel cell(PEMFC) and molten carbonate fuel cell(MCFC). ${ }^{1,2,26,34,35}$ The PEMFC consists of a pressure plate, insulator, current collector, separator, gasket and a membrane electrode assembly (MEA). In particular, the MEA which consists of the gas diffusion layer (GDL), catalyst layer and ion conducting membrane, is an essential element of fuel cells. A direct methanol fuel cell (DMFC) is a type of PEMFC that uses methanol as fuel. The basic operation of a DMFC consists of fuel as a water/methanol liquid and is supplied into the flow channel on the anode side of the separator. The DMFC diffuses through the anode GDL until it reaches the anode catalyst layer where it is converted into protons and electrons. The electrons are transported to the cathode via an external circuit and the protons are transported to the cathode through the electrolyte membrane. On the cathode side, the oxidant diffuses through the cathode GDL until it reaches the cathode catalyst layer. The oxygen is consumed by the protons and electrons transported from the anode, and liquid water is generated. All of the transport phenomena involve transportation loss that eventually reduces the performance of the fuel cells. Therefore, the transport paths must be designed carefully. This goal is achieved by careful control of the key material characteristics and the physical factors in a fuel cell such as the crossover effect, ${ }^{1-3,34}$ temperature effect, ${ }^{4,5}$ humidity and differential pressure effect, ${ }^{4,6}$ and compression force effect of the GDL. ${ }^{7-32}$ The optimization of the key components such as a GDL is critical to improve the performance of the DMFCs. Many studies have recently focused on the understanding of GDL characteristics. Gurau ${ }^{8}$ and $\mathrm{Lim}^{9}$ studied PEMFC performance with respect to the hydrophobic polymer content of a GDL. Their findings showed the possibility of performance control using hydrophobic polymer contents. Litster ${ }^{10}$ presented the visualization of the water transport in the GDL of a PEMFC using fluorescence microscopy. Pasaogullari ${ }^{10,11}$ analytically studied the transport phenomena of the water and electron in a GDL. Kong, ${ }^{13}$ Jordan, ${ }^{14,15}$ Lee $^{16}$ and Chu ${ }^{17}$ conducted various studies to verify the effect of the morphology variation of GDL by the versatile manufacturing method or treatment procedures. Besides the optimization of the material characteristics of the GDL, physical factors like compression pressure, compressed thickness, temperature distribution, and mass transport rate should be optimized to improve the stack performance without any change of materials. Hottinen ${ }^{19}$ conducted research on temperature distribution. The effect for the degree of compression on the GDL was investigated. ${ }^{18-32}$

Like this, the compression force and control of material contents of the 
GDL for optimization of the compression ratio have been the focus of many studies. Many researchers controlled compression ratio using an assembling force of stack or a compression of testing jig. In this study, we controlled compression ratio with an alternative method. The compression ratio of GDL is optimized by the variation of the compression force according to the design of the stack structure and the variation of PTFE gasket thickness. This is effective for preventing over-compression and sealing of the stack. We consider the effect of the compression ratio on the unit cell performance. The performance test of the unit DMFC is applied according to the variation of the compression ratio of the GDL at the cathode side by two different kinds of thicknesses of the current collectors. The compression using current collector which has valid thickness has some advantages. Previous method like using gasket thickness cannot avoid corrosion and contamination problems due to expose with fuel. Moreover, this method maintain valid compression during end-plate bending condition due to tensile force from assemble rod. This structure is acting like a disk spring. This condition directly affects the compression ratio at the central area of the GDL while various thicknesses of the PTFE gaskets are performed. We also use the amplitude of voltage fluctuation of the DMFC unit for quantization of mass transport loss, which shows what the unit DMFC relationship is between the pressure drop and the peak power.

\section{Methodology}

Fig. 1 shows the schematic diagram of the single cell of a DMFC. E-TEK's DMFC membrane electrolyte assemblies (MEA, 12D-W) with a $50 \mathrm{~cm}^{2}$ active area is used as a performance test in this research. 12D-W MEAs are manufactured by using DuPont ${ }^{\mathrm{TM}}$ Nafion ${ }^{\circledR} 117$ and carbon cloth GDLs. The catalyst loading on the anode side is $4.0 \mathrm{mg} /$ $\mathrm{cm}^{2}$ platinum Ruthenium Black, while the catalyst loading on the cathode side is $4.0 \mathrm{mg} / \mathrm{cm}^{2}$ platinum black. The total thickness of the MEA is about $1.17 \mathrm{~mm}$. To prevent over-compression of GDL, polytetrafluoroethylene (PTFE) skived sheets are used for the unit cell gasket. The PTFE gaskets on the cathode side are prepared with various thicknesses from $150 \mu \mathrm{m}$ to $300 \mu \mathrm{m}$. The flow fields of the air and fuel sides have serpentine channels and the open ratio between the channel and land width is 0.923 . The current collectors, which are the middle insert type in the insulator, was designed to prevent corrosion. There is a large gap between the manifold and the current collector. It is also easy to align with a single cell or stack and to control the compression ratio using the thickness of the current collector with a PTFE gasket.

The two types of thicknesses for the current collectors are manufactured to show the compression ratio effect. The thickness of the thin current collector and the groove of the insulator is $1.5 \mathrm{~mm}$. Fig. 1 (b) shows the schematic of installed current collector. Thickness of the thicker current collector and the groove of the insulator is $1.7 \mathrm{~mm}$. The insulators are made of epoxy glass and are used for isolation of electricity. The pressure plates have a thickness of $20 \mathrm{~mm}$ and are manufactured with duralumin. The assembly torque of the unit cell is $80 \mathrm{kgf}-\mathrm{cm}$. The stack specifications of these features are shown in Fig. 1.

The test station consists of a fuel supply, air supply and control parts. The methanol solution is supplied by using the metering pump. The pump concentration is controlled by using the calibrated FC6 Methanol Concentration-Density Meter, which has an accuracy of

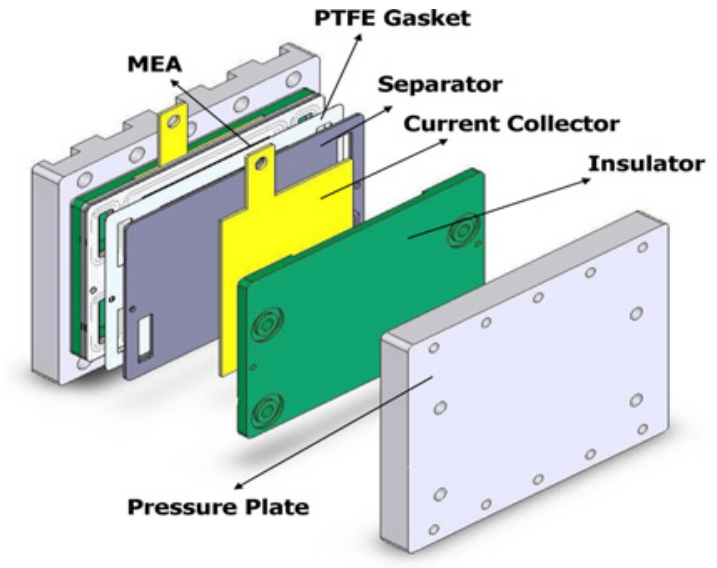

(a) Schematic diagram of the DMFC single cell

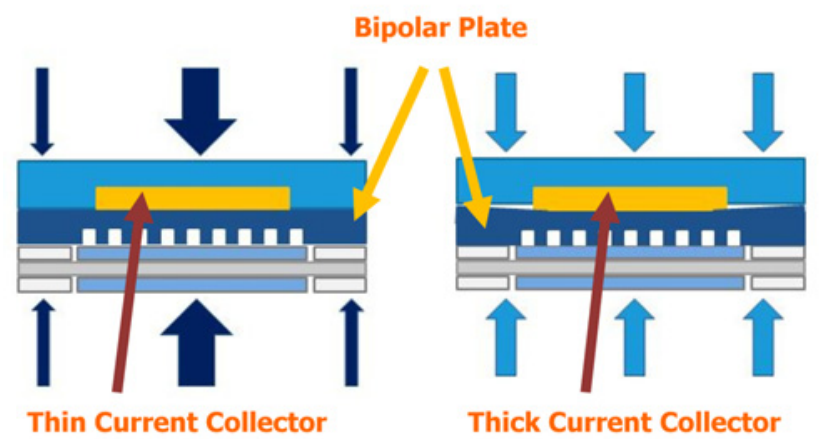

(b) Schematic about effect of thickness of current collector

Fig. 1 Single cell design of the DMFC

$\pm 0.3 \% \mathrm{w} / \mathrm{w}$. The fuel is $1 \mathrm{M}$ methanol solution and the fuel stoichiometric proportion is about $10 \mathrm{M}$ for decoupling the fuel side effect. Air is supplied by microbial fuel cells (MFC) with an accuracy of $0.1 \%$. The humidity of the air was controlled by a bubbler-type humidifier. The relative humidity is fixed at $60 \%$. Temperature is regulated by using a proportional-integral-derivative (PID) controller, and the operating temperature is $60^{\circ} \mathrm{C}$. Agilent N3300A DC electronic load and Agilent E3633A power supply are used for this work. The voltage and current data are acquired from National Instruments (NI) compactDAQ. The data on the temperature and pressure between the unit cell inlet and outlet are also obtained by using NI compactDAQ.

\section{Results}

\subsection{Control the Compression Ratio by Current Collectors}

To verify the effect of the compression ratio in the central area of the DMFC unit, the experiment is implemented by varying the thickness of the current collectors. The thicknesses of the current collectors are $1.5 \mathrm{~mm}$ and $1.7 \mathrm{~mm}$ and the assembly pressure is applied equally. Because the structure of the current collector is positioned in the middle part of the insulator, stress for the central area of the unit cell is concentrated. The performance could differ by the varying thickness of the current collector. Fig. 2 shows the unit cell performance for the varying thickness of the current collectors. The stoichiometric ratio of the air and fuel is fixed at 10 for decoupling the stoichiometric effect related with the amount of supplying the fuel and 


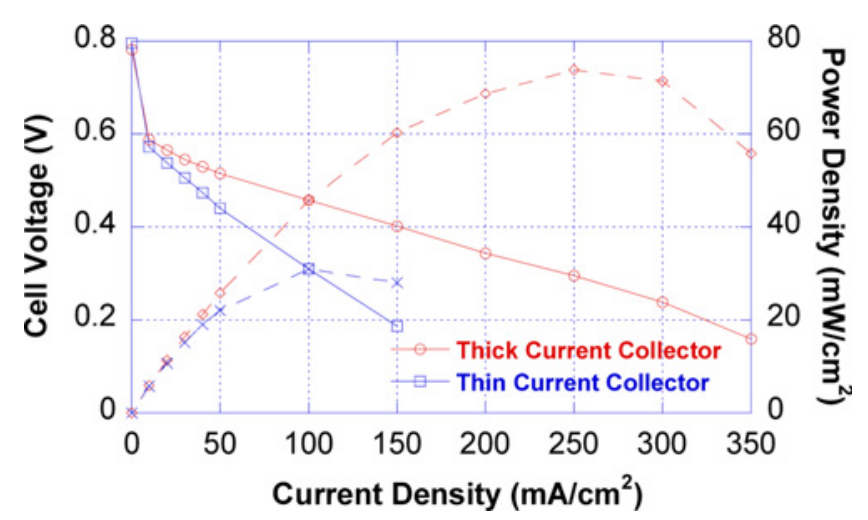

Fig. 2 Unit cell performance with respect to the thickness of the current collector

air. The operating temperature is about $60^{\circ} \mathrm{C}$ and the relative humidity is $60 \%$. The maximum power in the case of the $1.5 \mathrm{~mm}$ current collector thickness is about $30 \mathrm{~W}$. The maximum power in the case of the $1.7 \mathrm{~mm}$ current collector thickness is about $73 \mathrm{~W}$. The open circuit voltage (OCV) and activation loss seem to have approximately the same case. However, this result shows that the ohmic loss has a large difference for the performance between the two cases because of the different thickness of the current collectors. GDL is a porous material that has several important functions such as the transfer of the current and delivery of the fuel from the bulk site to the catalyst layer. The porosity of GDL is varied when the unit cell is assembled. Then, the performance of the unit cell differs according to varying porosity. This reflects the ohmic loss decreases and performance increases when the central area of the MEA using the $1.7 \mathrm{~mm}$ current collector thickness has more compression ratio than the other current collector thickness samples. An increasing compression ratio is an effective way for decreasing ohmic loss. However, it is ineffective for decreasing mass transport loss. It is difficult to transfer the oxidizer on the catalyst layer by decreasing the porosity of the GDL.

To show the effect of the mass transport with respect to the compression ratio, the unit cell is tested in terms of time with varying air flow rate and the varying thicknesses of the current collectors. Fig. 3 shows the results of the transient variation for the voltage varying the air flow rate. The unit cell is controlled with a constant current density of $100 \mathrm{~mA} / \mathrm{cm}^{2}$, and by varying the air flow rate. It means both of cases have same current density in same conditions like stoichiometry, reactant mass flux and product mass flux. The cell voltage is only experiment data. The transient variation of the voltage decreases by decreasing the air flow rate and the performance of the unit cell becomes low and unstable. Fig. 3(a) shows the transient variation of the voltage in the case of the $1.5 \mathrm{~mm}$ current collector thickness. Fig. 3(b) shows the transient variation of the voltage in the case of the $1.7 \mathrm{~mm}$ current collector thickness. Fig. 3(b) has a higher voltage than Fig. 3(a). However, the amplitude of the voltage fluctuation augments. It is considered that flooding issue in the case of thick current collector. Although, both of cases were controlled same reactant and product mass flux by constant current operation and flow rate, the difference of compression ratio affects microstructure of GDL and area size of flow channel between GLD and separator. These changes of structure affect to stability because of increasing mass transport loss on the cathode

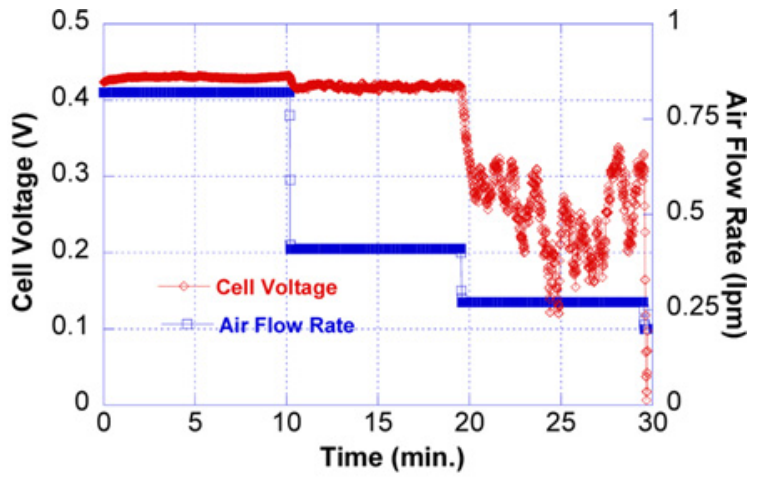

(a) Current collector thickness, $1.5 \mathrm{~mm}$

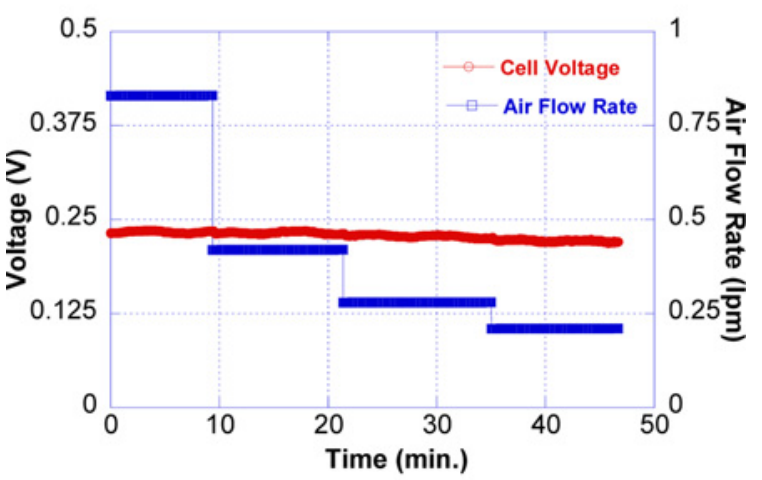

(b) Current collector thickness, $1.7 \mathrm{~mm}$

Fig. 3 Transient variation of the voltage with respect to stoichiometry in constant current operation $\left(100 \mathrm{~mA} / \mathrm{cm}^{2}\right)$

side. Fig. 3(b) also shows that is difficult to operate behind a 0.27 LPM air flow rate. Conversely, Fig. 3(a) shows that it can operate in all regions of the air flow rate, although the performance is lower than Fig. 3(b). This reflects the effect of the mass transport, which directly depends on the compression ratio. The performance increases with a decreasing ohmic loss when the central area of the MEA has a higher compression ratio. On the other hand, the stabilities of the performance decrease with increasing compression ratio because the porosity of GDL decreases. As mentioned above, increasing the compression ratio is an effective way for decreasing ohmic loss. However, it is ineffective for decreasing mass transport loss. Decreasing porosity of the GDL makes it difficult to transfer the fuel on the catalyst layer from the bulk side.

Fig. 3 shows decreasing porosity directly affects mass transport loss and produces a voltage fluctuation. There is difficulty in the transportation of the oxidizer on the catalyst layer from the bulk side. This voltage fluctuation provides useful information about mass transport loss on the performance of the unit cell. To verify the quantitative effect of the mass transport loss, the results from fast Fourier transform (FFT) analysis are performed. Then, the fluctuation of the voltage is normalized by the mean value of the voltage. Finally, the results from the FFT analysis of the voltage variation at a $100 \mathrm{~mA} / \mathrm{cm}^{2}$ current density are integrated with each frequency, which shows the fluctuation amplitude of the voltage. ${ }^{33}$

Fig. 4 shows the results of the amplitude of the voltage fluctuation for each air flow rate. This reflects that the voltage fluctuation increases with a decreasing air flow rate, which means that the mass transport loss increases with a decreasing air flow rate. This analysis shows the 


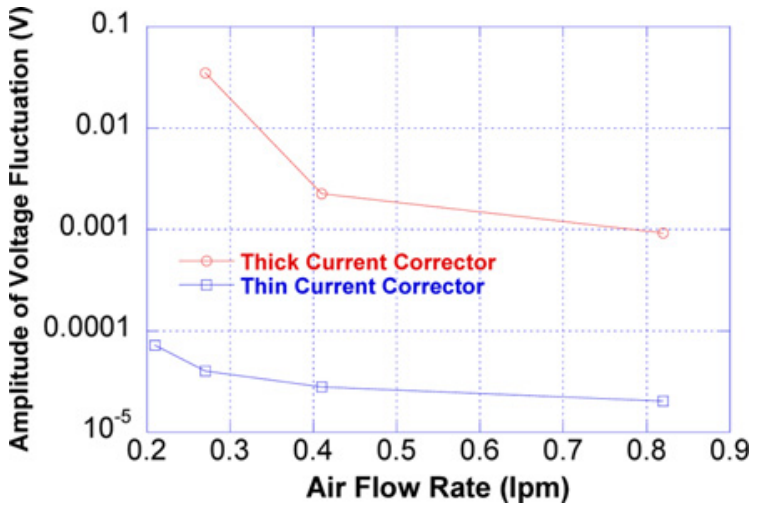

Fig. 4 Amplitude of the voltage fluctuation with respect to air flow rate

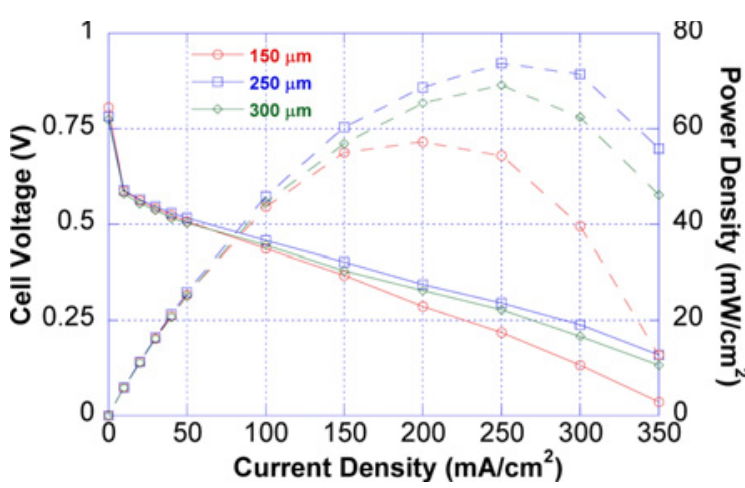

Fig. 5 Unit cell performance with respect to thickness of the GDL

possibility for a quantitative amount of the mass transport loss and reflects that the unit cell can have a large difference on the amplitude of the voltage fluctuation with the variation of the current collector thickness. In particular, the amplitude of the voltage fluctuation in the case of the $1.7 \mathrm{~mm}$ current collector thickness, the current collector increases exponentially more than in the case of the $1.5 \mathrm{~mm}$ current collector thickness for all regions of air flow rate. The results show that the effect of the thickness of the current collector directly affects the mass transport loss, and that the compression ratio of the GDL can change the porosity of the current collector. The characteristic of the GDL is changed by these effects, and subsequently, the performance is varied.

As shown in Fig. 3 and 4, the thick current collector has better performance because of a decreasing ohmic loss with more compression ratio. However, the mass transport loss increases because the porosity of the GDL decreases. This makes the voltage fluctuation increase, which means that the stability of the unit cell decreases with an increasing compression ratio.

\subsection{Control the Compression Ratio by PTFE Gasket}

There are some ways to change the compression ratio of the GDL, which compresses more of the central area of the unit cell while using a current collector and changing the PTFE gasket thickness.

The PTFE gasket is usually used for sealing and spacing and thus prevents the over-compression of the GDL. The change of the PTFE gasket thickness can be another way to control the unit cell performance with the compression ratio of the GDL. Fig. 5 shows the unit cell performance for the PTFE gasket thickness of the unit cell.

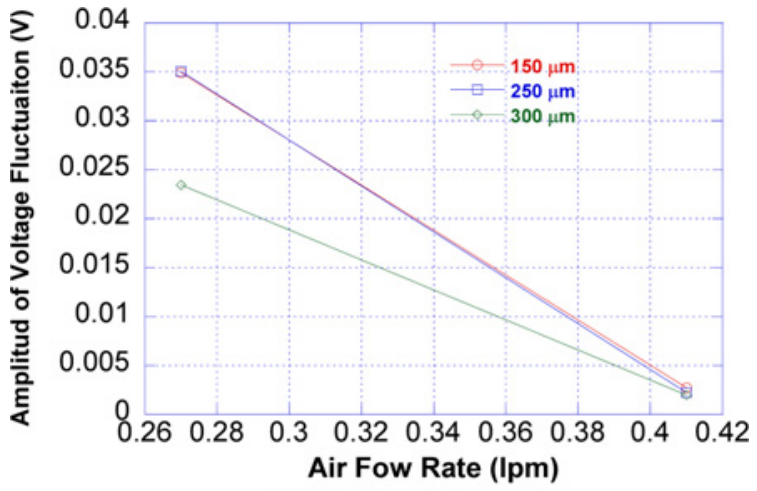

(a) Varying air flow rate

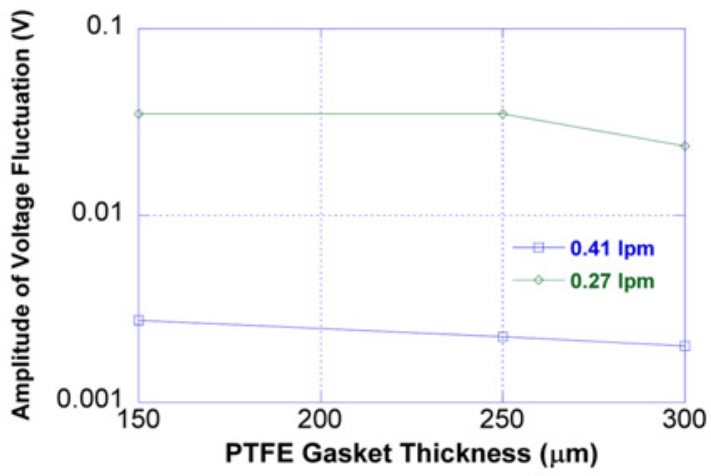

(b) Varying PTFE gasket thickness

Fig. 6 Amplitude of the voltage fluctuation with respect to the PTFE gasket thickness

The stoichiometric ratio of the air and fuel is fixed at 10 for decoupling the stoichiometric effect related with the effect of the fuel and air. The operating temperature is about $60^{\circ} \mathrm{C}$ and the relative humidity is $60 \%$. The OCVs and activation loss in all cases look similar. However, the unit cell has different performance because of the mixing of the ohmic loss and mass transport loss. The performance of the unit cell increases in the case of the $150 \mu \mathrm{m}$ to $250 \mu \mathrm{m}$ current collector thicknesses. However, performance decreases in the case of the $250 \mu \mathrm{m}$ to $300 \mu \mathrm{m}$ current collector thicknesses. The unit cell using the $250 \mu \mathrm{m}$ PTFE gasket thickness has a maximum power of $72 \mathrm{~mW} / \mathrm{cm}^{2}$. This gives rise to vary the porosity of the GDL and compression ratio. Although there is an optimal performance, it is not easy to know what the major effects in losses are.

To show the effect of the mass transport loss for varying the PTFE gasket thickness, the unit cell is tested with varying the air flow rate. Fig. 6 shows the results the amplitude of the voltage fluctuation in the case of $150 \mu \mathrm{m}, 250 \mu \mathrm{m}$ and $300 \mu \mathrm{m}$ PTFE gasket thickness. The unit cell is controlled with a fixed current density of $100 \mathrm{~mA} / \mathrm{cm}^{2}$ and by air flow rate. Fig. 6(a) shows the amplitude of voltage fluctuation with varying air flow rate. The $300 \mu \mathrm{m}$ PTFE gasket thickness has smaller amplitude of voltage fluctuation than the other PTFE gasket thicknesses with a decreasing air flow rate from $0.41 \mathrm{lpm}$ to $0.27 \mathrm{lpm}$. The amplitude of voltage fluctuation below a $250 \mu \mathrm{m}$ PTFE gasket thickness has around $35 \mathrm{mV}$ fluctuation, which has more than $10 \mathrm{mV}$ of voltage fluctuation compared to the other PTFE gasket thicknesses. Conversely, the amount of the voltage fluctuations looks the same below $250 \mu \mathrm{m}$ PTFE gasket thickness, which means that the mass transport loss in the case of above $300 \mu \mathrm{m}$ gasket thickness is relatively low and the voltage 


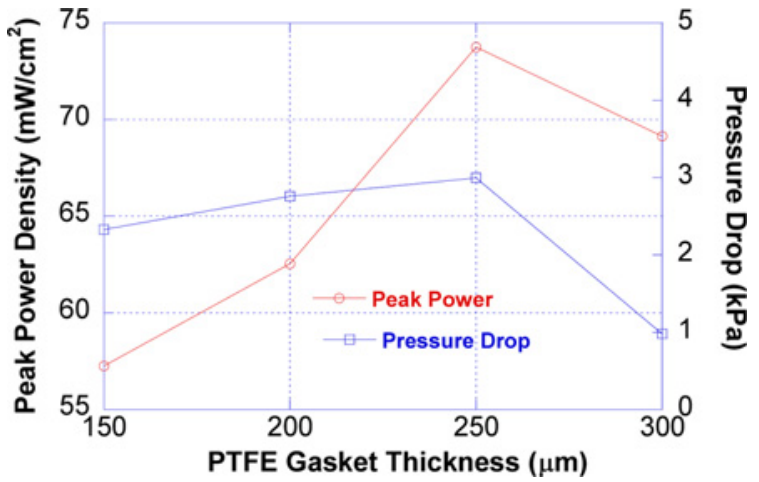

Fig. 7 Peak power density and pressure drop with respect to the PTFE gasket thickness

fluctuation while increasing air flow rate decreases. On the contrary, the ohmic loss in the case of using the 300ìm PTFE gasket thickness is larger than the other PTFE gasket thicknesses. Fig. 6(b) shows the amplitude of voltage fluctuation with varying PTFE gasket thickness. The amplitude of voltage fluctuation increases with decreasing PTFE gasket thickness. However, it has the same amplitude below a $250 \mu \mathrm{m}$ PTFE gasket thickness at an air flow rate of $0.41 \mathrm{lpm}$. Fig. 6(b) shows that the PTFE gasket thickness affects the mass transport loss even if the air flow rate increases. However, a differential effect between the different PTFE gasket thicknesses looks small at the higher air flow rate region.

The unit cell performance depends on the channel pressure drop that is directly affected by the compression ratio because of the GDL bending rate inside the channel. ${ }^{18,32,33}$ The pressure drop starts to increase with an increasing compression ratio until the elastic region. To illustrate the compression ratio effect in the channel, Fig. 5 shows the peak power density and pressure drop in the unit cell for the various PTFE gasket thicknesses. Fig. 5 and 7 show the unit cell with the 250im PTFE gasket thickness has the best performance. The peak power density increases while increasing the PTFE gasket thickness from $300 \mu \mathrm{m}$ to $250 \mu \mathrm{m}$, and dramatically decreases while increasing the gasket thickness. The unit cell with a $250 \mu \mathrm{m}$ PTFE gasket thickness has the highest pressure drop. This is a very similar pressure drop pattern that increases while increasing the PTFE gasket thickness until $250 \mu \mathrm{m}$, and then decreases while increasing the PTFE gasket thickness. However, the pressure drop has a gentle slope between the PTFE gasket thickness of $150 \mu \mathrm{m}$ and $250 \mu \mathrm{m}$ compared to the drastic slope region between $250 \mu \mathrm{m}$ and $300 \mu \mathrm{m}$. All things considered from Fig. 6 and 7, the PTFE gasket thickness has an elastic region limitation at $250 \mu \mathrm{m}$. The pressure drop and the amplitude of voltage fluctuation drastically decrease with an increasing gasket thickness above $250 \mu \mathrm{m}$. A $250 \mu \mathrm{m}$ gasket thickness is almost the compression ratio limitation for this unit cell.

\section{Conclusions}

We verified in this study that the effect of the compression ratio on the cathode side directly influences fuel cell performance. The gas diffusion layer is a key element of the fuel cell. The characteristics of the gas diffusion layer directly affect fuel cell performance. This paper suggests a way to show the amount of mass transport loss by amplitude of voltage fluctuation. We also show that there is a relationship between the pressure drop and peak power of the unit cell. Studies have indicated an effective way to control the compression ratio of the gas diffusion layer, which are the design of the stack structure such as the control of the current collector thickness without any change of compression force and control of the gasket thickness. Experimental results on varying the thickness of current collectors reflect a very efficient way to decrease the ohmic loss by concentration of the compression force at the central area of the unit cell. However, an over-compressed central area of the stack can affect an increasing mass transport loss. The transient voltage variation is more fluctuated with a decreasing air flow rate because of the over-compression ratio in this research.

The controlled PTFE gasket thickness is another effective way to control the compression ratio of the gas diffusion layer. The results show the unit cell of the direct methanol fuel cell has an optimal point using proper PTFE gasket thickness of $250 \mu \mathrm{m}$. The performance increases with a decreasing gasket thickness up to $250 \mu \mathrm{m}$ because the gas diffusion layer is well-compressed down. The performance decreases with decreasing gasket thickness under $250 \mu \mathrm{m}$ because the gas diffusion layer is damaged from an over-compression ratio. This gives rise to the ohmic loss decreasing up to $250 \mu \mathrm{m}$ however decreasing the porosity of the gas diffusion layer, which affects the mass transport loss of the air. As a result, the unit cell can be optimized by control of the current collectors and PTFE gasket thickness. The membrane electrode assembly condition by the amplitude of voltage fluctuation and pressure drop can also be identified.

\section{ACKNOWLEDGEMENT}

This work was partially supported by the Global Frontier R\&D Program in the Center for Multiscale Energy System funded by the National Research Foundation under the Ministry of Education, Science and Technology, Korea (2011-0031569). This research was also partially supported by National Research Foundation of Korea (Grant No. 2011-0029576) contracted through the Institute of Advanced Machinery and Design at Seoul National University.

\section{REFERENCES}

1. Cruickshank, J. and Scott, K., "The Degree and Effect of Methanol Crossover in the Direct Methanol Fuel Cell," Journal of Power Sources, Vol. 70, No. 1, pp. 40-47, 1998.

2. Kjeang, E., Goldak, J., Golriz, M. R., Gu, J., James, D., et al., “A Parametric Study of Methanol Crossover in a Flowing Electrolytedirect Methanol Fuel Cell," Journal of Power Sources, Vol. 153, No. 1, pp. 89-99, 2006.

3. Du, C. Y., Zhao, T. S., and Yang, W., "Effect of Methanol Crossover on the Cathode Behavior of a DMFC: A Half-cell Investigation," Electrochimica Acta, Vol. 52, No. 16, pp. 5266-5271, 2007.

4. Chen, C., Shiu, J., and Lee, Y., "Development of a Small DMFC Bipolar Plate Stack for Portable Applications," Journal of Power Sources, Vol. 159, No. 2, pp. 1042-1047, 2006. 
5. Liu, Y., Xie, X., Shang, Y., Li, R., Qi, L., et al., "Power Characteristics and Fluid Transfer in 40W Direct Methanol Fuel Cell Stack," Journal of Power Sources, Vol. 164, No. 1, pp. 322-327, 2007.

6. Hwang, Y. S., Lee, D. Y., Kim, S. Y., Cha, S. W., and Choi, H., "Influence of Flow Channel Design on the Flow Pressure Drop and the Performance of Direct Methanol Fuel Cells," Journal of Fuel Cell Science and Technology, Vol. 6, No. 1, Paper No. 011023, 2009.

7. Gurau, V., Bluemle, M. J., De Castro, E. S., Tsou, Y. M., Mann Jr, J. A., et al., "Characterization of Transport Properties in Gas Diffusion Layers for Proton Exchange Membrane Fuel Cells: 1. Wettability (Internal Contact Angle to Water and Surface Energy of GDL Fibers)," Journal of Power Sources, Vol. 160, No. 2, pp. 1156-1162, 2006.

8. Gurau, V., Bluemle, M. J., De Castro, E. S., Tsou, Y. M., Zawodzinski Jr, T. A., et al., "Characterization of Transport Properties in Gas Diffusion Layers for Proton Exchange Membrane Fuel Cells: 2. Absolute Permeability," Journal of Power Sources, Vol. 165, No. 2, pp. 793-802, 2007.

9. Lim, C. and Wang, C., "Effects of Hydrophobic Polymer Content in GDL on Power Performance of a PEM Fuel Cell," Electrochimica Acta, Vol. 49, No. 24, pp. 4149-4156, 2004.

10. Litster, S., Sinton, D., and Djilali, N., "Ex Situ Visualization of Liquid Water Transport in PEM Fuel Cell Gas Diffusion Layers," Journal of Power Sources, Vol. 154, No. 1, pp. 95-105, 2006.

11. Pasaogullari, U. and Wang, C., "Liquid Water Transport in Gas Diffusion Layer of Polymer Electrolyte Fuel Cells," Journal of the Electrochemical Society, Vol. 151, No. 3, pp. A399-A406, 2004.

12. Pasaogullari, U., Mukherjee, P. P., Wang, C. Y., and Chen, K. S., "Anisotropic Heat and Water Transport in a PEFC Cathode Gas Diffusion Layer," Journal of The Electrochemical Society, Vol. 154, No. 8, pp. B823-B834, 2007.

13. Kong, C. S., Kim, D. Y., Lee, H. K., Shul, Y. G., and Lee, T. H., "Influence of Pore-size Distribution of Diffusion Layer on Masstransport Problems of Proton Exchange Membrane Fuel Cells," Journal of Power Sources, Vol. 108, No. 1, pp. 185-191, 2002.

14. Jordan, L., Shukla, A., Behrsing, T., Avery, N., Muddle, B., et al., "Effect of Diffusion-layer Morphology on the Performance of Polymer Electrolyte Fuel Cells Operating at Atmospheric Pressure," Journal of Applied Electrochemistry, Vol. 30, No. 6, pp. 641-646, 2000.

15. Jordan, L., Shukla, A., Behrsing, T., Avery, N., Muddle, B., and Forsyth, M., "Diffusion Layer Parameters Influencing Optimal Fuel Cell Performance," Journal of Power Sources, Vol. 86, No. 1, pp. 250-254, 2000.

16. Lee, H. K., Park, J. H., Kim, D. Y., and Lee, T. H., "A Study on the Characteristics of the Diffusion Layer Thickness and Porosity of the PEMFC,” Journal of Power Sources, Vol. 131, No. 1, pp. 200-206, 2004.
17. Chu, H. S., Yeh, C., and Chen, F., "Effects of Porosity Change of Gas Diffuser on Performance of Proton Exchange Membrane Fuel Cell,” Journal of Power Sources, Vol. 123, No. 1, pp. 1-9, 2003.

18. Su, Z., Liu, C., Chang, H., Li, C., Huang, K., et al., “A Numerical Investigation of the Effects of Compression Force on PEM Fuel Cell Performance," Journal of Power Sources, Vol. 183, No. 1, pp. 182192, 2008.

19. Hottinen, T. and Himanen, O., "Pemfc Temperature Distribution Caused by Inhomogeneous Compression of GDL," Electrochemistry Communications, Vol. 9, No. 5, pp. 1047-1052, 2007.

20. Escribano, S., Blachot, J. F., Ethève, J., Morin, A., and Mosdale, R., "Characterization of PEMFCs Gas Diffusion Layers Properties," Journal of Power Sources, Vol. 156, No. 1, pp. 8-13, 2006.

21. Lee, W. K., Ho, C. H., van Zee, J., and Murthy, M., "The Effects of Compression and Gas Diffusion Layers on the Performance of a PEM Fuel Cell,” Journal of Power Sources, Vol. 84, No. 1, pp. 4551, 1999.

22. Ge, J., Higier, A., and Liu, H., "Effect of Gas Diffusion Layer Compression on PEM Fuel Cell Performance," Journal of Power Sources, Vol. 159, No. 2, pp. 922-927, 2006.

23. Sui, P. and Djilali, N., "Analysis of Coupled Electron and Mass Transport in the Gas diffusion Layer of a PEM Fuel Cell,” Journal of Power Sources, Vol. 161, No. 1, pp. 294-300, 2006.

24. Sun, W., Peppley, B. A., and Karan, K., "Modeling the Influence of GDL and Flow-field Plate Parameters on the Reaction Distribution in the PEMFC Cathode Catalyst Layer," Journal of Power Sources, Vol. 144, No. 1, pp. 42-53, 2005.

25. Yi, J. S. and van Nguyen, T., "Multicomponent Transport in Porous Electrodes of Proton Exchange Membrane Fuel Cells using the Interdigitated Gas Distributors," Journal of The Electrochemical Society, Vol. 146, No. 1, pp. 38-45, 1999.

26. Zhou, P., Wu, C., and Ma, G., "Influence of Clamping Force on the Performance of PEMFCs," Journal of Power Sources, Vol. 163, No. 2, pp. 874-881, 2007.

27. Zhou, P. and Wu, C., "Numerical Study on the Compression Effect of Gas Diffusion Layer on PEMFC Performance," Journal of Power Sources, Vol. 170, No. 1, pp. 93-100, 2007.

28. Nitta, I., Hottinen, T., Himanen, O., and Mikkola, M., "Inhomogeneous Compression of PEMFC Gas Diffusion layer: Part I. Experimental," Journal of Power Sources, Vol. 171, No. 1, pp. 2636, 2007.

29. Hottinen, T., Himanen, O., Karvonen, S., and Nitta, I., "Inhomogeneous Compression of PEMFC Gas Diffusion Layer: Part II. Modeling the Effect," Journal of Power Sources, Vol. 171, No. 1, pp. 113-121, 2007.

30. Zhu, Y., Liu, C., Liang, J., and Wang, L., "Investigation of the Effects of Compression Pressure on Direct Methanol Fuel Cell," Journal of Power Sources, Vol. 196, No. 1, pp. 264-269, 2011. 
31. Choi, H., Hwang, Y. S., Lee, D. Y., Kim, S. Y., and Cha, S. W., "Effect of Cathode Gasket Thickness to Performance of Direct Methanol Fuel Cells", Proc. of the ASME 6th International Conference on Fuel Cell Science, Engineering and Technology, Paper No. FuelCell2008-65067, pp. 865-870, 2008.

32. Kuan, Y. D. and Chang, C. H., "Experimental Investigation on the Process-induced Damage of a Direct Methanol Fuel Cell Assembled by the Printed Circuit Board Technique," Journal of Fuel Cell Science and Technology, Vol. 6, No. 1, Paper No. 011016, 2009.

33. Hwang, Y. S., Lee, D. Y., Kim, S. Y., Cha, S. W., and Choi, H., "Influence of Flow Channel Design on the Flow Pressure Drop and the Performance of Direct Methanol Fuel Cells," Journal of Fuel Cell Science and Technology, Vol. 6, No. 1, Paper No. 011023, 2009.

34. Choi, H., Cho, G. Y., and Cha, S. W., "Fabrication and Characterization of Anode Supported YSZ/GDC Bilayer Electrolyte SOFC using Dry Press Process,” Int. J. Precis. Eng. Manuf.-Green Tech., Vol. 1, No. 2, pp. 95-99, 2014.

35. Seo, Y. H., Kim, H. J., Jang, W. K., and Kim, B. H., "Development of Active Breathing Micro PEM Fuel Cell,” Int. J. Precis. Eng. Manuf.-Green Tech., Vol. 1, No. 2, pp. 101-106, 2014. 